\title{
Forming limit curve determination of AA6061-T6 aluminum alloy sheet
}

\author{
Nguyen Huu Hao, Nguyen Ngoc Trung, and Vu Cong Hoa
}

\begin{abstract}
The forming limit curve (FLC) is used in sheet metal forming analysis to determine the critical strain or stress values at which the sheet metal is failing when it is under the plastic deformation process, e.g. deep drawing process. In this paper, the FLC of the AA6061-T6 aluminum alloy sheet is predicted by using a micro-mechanistic constitutive model. The proposed constitutive model is implemented via a vectorized user-defined material subroutine (VUMAT) and integrated with finite element code in ABAQUS/Explicit software. The mechanical behavior of AA6061-T6 sheet is determined by the tensile tests. The material parameters of damage model are identified based on semi-experience method. To archive the various strain states, the numerical simulation is conducted for the Nakajima test and then the inverse parabolic fit technique that based on ISO 124004-2:2008 standrad is used to extracted the limit strain values. The numerical results are compared with the those of $M$ K, Hill and Swift analytical models.
\end{abstract}

Index Terms - forming limit curve, void growth, Nakajima drawing, Dung model.

\section{INTRODUCTION}

$\mathrm{O}$ ver many years, the aluminum alloy sheets was widely applied in automotive and civil industries because of their outstanding advantages in high strength and light weight. Therefore, it is necessary to accurately describe their forming behaviors at large strains.

Manuscript Received on July $13^{\text {th }}$, 2016. Manuscript Revised December $06^{\text {th }}, 2016$.

This research is funded by Vietnam National University Ho Chi Minh City (VNU-HCM) under grant number C2017-20-05.

Nguyen Huu Hao author is with the Engineering Mechanics Department, Ho Chi Minh City University of Technology, VNU-HCM, Vietnam (e-mail: nguyenhuuhao@tdnu.edu.vn).

Nguyen Ngoc Trung author is with School of Mechanical Engineering, 585 Purdue Mall, ME3011, Purdue University, West Lafayette, IN 47907, USA. (e-mail: trungnguyen@perdue.edu).

$\mathrm{Vu}$ Cong Hoa is with the Engineering Mechanics Department, Ho Chi Minh City University of Technology, VNU-HCM, Vietnam (e-mail: vuconghoa@hcmut.edu.vn).
The FLC curve is usually predicted by the Marciniak-Kuczynski (M-K) theory model [1] that based on an inconsistency in sheet. Beside the FLC theory prediction, the Nakajima deep drawing model is also applied widely in experiment and numerical simulation to determine the forming limit curve. Accordingly, the Nakajima test is usually conducted for the several specimens to find the various strain paths that presents forming response of material from uniaxial to biaxial stretched loading state. In this method, the limit strains are determined by an inverse parabolic fit $[2,3]$ or time-dependent technique $[2,4]$ at or after the onset of necking.

The ductile fracture mechanism of metallic materials and their alloys has been proved to be due to the micro-void nucleation, growth and coalescence in matrix material $[5,6]$. A cylindrical micro-void growth in rigid-plastic material based ductile fracture criterion was proposed by McClintock [5]. Dung [7] has modified the McClintock model for the ellipsoidal and cylindrical void growth in hardening matrix material under the remoted stress field and has proposed a constitutive model for porous ductile material. Employing a ductile fracture model to predict FLC is widely applied because it is considered as an effective remedy for saving more time than that of the experiment $[3,8]$.

In this study, we use a Dung's porous ductile material model [7], conjugated with the Hill'48 quadratic yield function to predict the FLC of AA6061-T6 aluminum alloy. The ductile fracture model is implemented by a vectorized user-defined material subroutine (VUMAT) in ABAQUS/Explicit software package. The seven specimens with various waist width would be used to numerical simulation and then the limit strains were attained by the inverse parabolic fit in accordance with ISO 12004-2:2008 standard. The present results are compared with the those of theory FLC models. 


\section{CONSTITUTIVE MODEL}

The sheet metal is usually showing an anisotropy so that the von Mises equivalent stress function in the original Dung's model [7] is replaced by the Hill48 quadratic criterion [9].

$$
\begin{aligned}
& \sigma_{e}=\left[F\left(\sigma_{22}-\sigma_{33}\right)^{2}+G\left(\sigma_{33}-\sigma_{11}\right)^{2}\right. \\
& \left.+H\left(\sigma_{11}-\sigma_{22}\right)^{2}+2 L \sigma_{23}^{2}+2 M \sigma_{31}^{2}+2 N \sigma_{12}^{2}\right]^{1 / 2}
\end{aligned}
$$

Here $\sigma_{i j} \quad(i, j=1,2,3)$ are components of Cauchy stress tensor, $F, G, H, L, M, N$ are anisotropic coefficients.

$$
\begin{aligned}
& F=\frac{R_{0}}{R_{90}\left(R_{0}+1\right)}, G=\frac{1}{R_{0}+1}, H=\frac{R_{0}}{R_{0}+1}, \\
& N=\frac{\left(R_{0}+R_{90}\right)\left(1+2 R_{45}\right)}{2 R_{90}\left(1+R_{0}\right)}, L=M=\frac{3}{2}
\end{aligned}
$$

The Lankford's coefficients $R_{0}, R_{45}$ and $R_{90}$ are determined by uniaxial tensile tests at $0^{\circ}, 45^{\circ}$ and $90^{\circ}$ in rolling direction.

Noting that for isotropic material, the Lankford's coefficients $R_{0}=R_{45}=R_{90}=1$, stress equivalent Hill'48 becomes stress equivalent von Mises [10].

The hardening rule of matrix material,

$$
\sigma_{f}=f\left(\bar{\varepsilon}^{p}\right)
$$

Here $\bar{\varepsilon}^{p}$ is equivalent plastic strain of matrix material.

Gurson [11] has been introduced a yield function based on mechanism of void nucleation, growth and coalescences in matrix material. Based on McClintock's void growth model [5], Dung [7] proposed not only a yield function that similar to Gurson-Tvergaard-Needleman (GTN) model [12] but also addition of a explicitly hardening parameter $n$ to consider hardening effects of matrix material under deformation as follow:

$$
\Phi=\frac{\sigma_{e}^{2}}{\sigma_{f}^{2}}+2 f^{*} q_{1} \cosh \left[\frac{\sqrt{3}(1-n) \sigma_{i j} \delta_{i j}}{3 \sigma_{f}}\right]-1-\left(q_{2} f^{*}\right)^{2}
$$

Where, the parameters $q_{1}, q_{2}$ are proposed by Tvergaard and Needleman [12], $n$ is hardening exponent of matrix material, $\sigma_{e}$ is Hill'48 equivalent stress, $f^{*}$ is function of void volume fraction (VVF), $\delta_{i j}$ is delta Kronecker.

$$
f^{*}= \begin{cases}f & \text { if } f \leq f_{c} \\ f_{c}+\frac{f_{F}-f_{c}}{f_{u}-f_{c}}\left(f-f_{c}\right) & \text { if } f_{c}<f \leq f_{F}\end{cases}
$$

Here $f_{c}$ and $f_{F}$ are critical and onset of fracture void volume fraction, respectively, $f_{u}=q_{1} / q_{2}$ is ultimate void volume fraction.

The evolution of void volume fraction is computed as follow:

$$
d f=d f_{\text {growth }}+d f_{\text {nucleation }}
$$

Here, the void volume fraction growth of the presence voids in matrix material:

$$
d f_{\text {growth }}=\left(1-f^{*}\right) d \varepsilon_{i j}^{p} \delta_{i j}
$$

Here $d \varepsilon_{i j}^{p}$ is plastic strain rate tensor.

The evolution of nucleated void volume fraction during matrix material under deformation:

$$
d f_{\text {nucleation }}=A d \bar{\varepsilon}^{p}
$$

The number of nucleated voids $A$ is a function of equivalent plastic strain of matrix material.

$$
A=\frac{f_{N}}{s_{N} \sqrt{2 \pi}} \exp \left[-\frac{1}{2}\left(\frac{\bar{\varepsilon}^{p}-\varepsilon_{N}}{s_{N}}\right)^{2}\right]
$$

Where, $f_{N}, s_{N}, \varepsilon_{N}$ are the parameters relative to the void nucleation during matrix material under deformation.

\section{NUMERICAL IMPLEMENTATION}

Based on the numerical algorithm of Aravas [13], the Dung's porous ductile model is implemented by a vectorized user-defined subroutine (VUMAT) and conjugated with finite element code of ABAQUS/Explicit software. The implemented procedure for Dung's model has been completed by Hao et al. [14].

\section{EXPERIMENTAL WORKS}

The experimental works adopted in this section to identify the mechanical behavior of AA6061-T6 aluminum alloy. The specimens to be designed and tested according to the ASTM-E8 standard [15].

Tensile tests were accomplished with a thin sheet that its nominal thickness of $2.0 \mathrm{~mm}$. To identify Lankford's coefficients $\left(R_{0}, R_{45}, R_{90}\right)$, having least three dog-bone specimens on each direction of the rolling, transverse and 45 degrees to rolling direction have used. The initial length of the gage marks is $50 \mathrm{~mm}$ for all tests. The geometry and dimension of dog-bone specimen are given in Figure 1. 


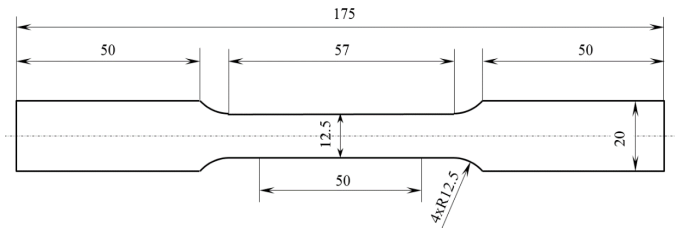

Figure 1 Dog-bone specimen

The tensile tests help to obtain the mechanical properties of AA6061-T6 aluminum alloy as shown in TABLE 1. The difference of engineering stressstrain behavior in three directions of $0^{\circ}, 45^{\circ}, 90^{\circ}$ to rolling direction is presented as Figure 2 . The true strain-stress curve that used to fit Swift hardening rule is given in Figure 3.

Assuming that the isotropic hardening rule obeys Swift model [16], fitting true strain-stress curve, the hardening parameters $\left(K, \varepsilon_{0}, n\right)$ is obtained as TABLE. The Lankford's coefficients are calculated by the eq. (10).

TABLE 1

MECHANICAL PROPERTIES OF AA6061-T6 ALUMINUM

\begin{tabular}{ccc}
\multicolumn{3}{c}{ ALLOY } \\
\hline \hline $\begin{array}{c}\text { Young's } \\
\text { modulus } \\
(E)\end{array}$ & Yield & $\begin{array}{c}\text { Poisson's } \\
\text { stress } \\
(v)\end{array}$ \\
\hline $74.6 \mathrm{GPa}$ & $244 \mathrm{MPa}$ & 0.314
\end{tabular}

$$
R_{\theta}=\frac{\varepsilon_{2}}{\varepsilon_{3}}=\frac{\ln \left(w_{f} / w_{0}\right)}{\ln \left(l_{0} w_{0} / l_{f} w_{f}\right)}
$$

Where $\varepsilon_{2}$ and $\varepsilon_{3}$ are the transverse and normal strains, respectively. $l_{0}, l_{f}, w_{0}, w_{f}(0$ and $f$ indexes imply initial and final values) are the gage length and width of dog-bone specimen, $\theta=0^{\circ}, 45^{\circ}, 90^{\circ}$.

TABLE 2

MATERIAL PARAMETERS OF AA6061-T6 ALUMINUM

\begin{tabular}{cccccc}
\multicolumn{3}{c}{ ALLOY } \\
\hline \hline \multirow{3}{*}{$K(\mathrm{MPa})$} & \multirow{2}{*}{$\varepsilon_{0}$} & \multirow{2}{*}{$n$} & \multicolumn{3}{c}{$\begin{array}{c}\text { Lankford's } \\
\text { coefficients }\end{array}$} \\
\cline { 3 - 7 } & & & $R_{0}$ & $R_{45}$ & $R_{90}$ \\
\hline 489.74 & 0.02 & 0.179 & 0.55 & 0.52 & 0.53 \\
\hline
\end{tabular}

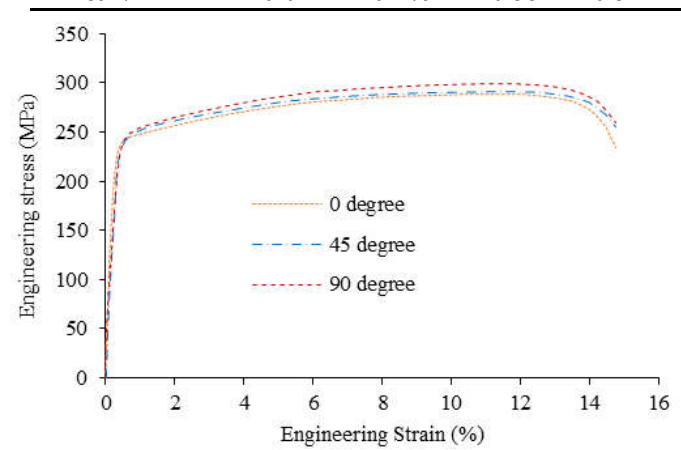

Figure 2. Experimental load behavior in various directions

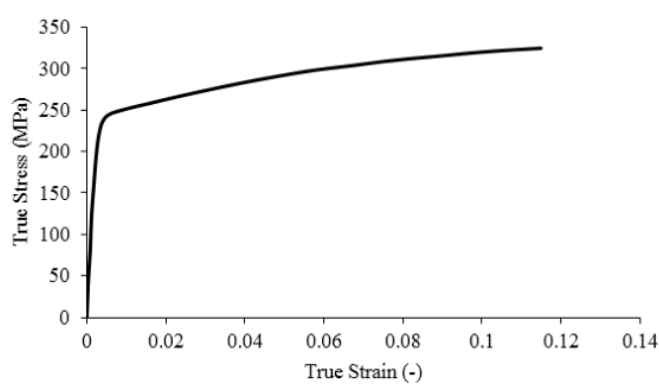

Figure 3. True stress-strain curve

\section{PARAMETER CALIBRATION}

To apply the porous plastic material model to prediction of ductile fracture, 8 parameters $\left(q_{1}, q_{2}, f_{F}, f_{C}, f_{0}, \varepsilon_{N}, s_{N}, f_{n}\right)$ must be identified. In general, any identification procedure that used to identify all these parameters would be still requirement of the computational time cost. In addition, for each material type, may be have more one set of material parameter (non-uniqueness of the solution) [17-19]. A literature review of material parameter identification for porous ductile model is necessary in this work. On that basis, the material parameters can be selected and calibrated for Dung's model.

Two parameters $q_{1}=1.5$ and $q_{2}=q_{1}^{2}=2.25$ that proposed by Tvergaard [20] to correct result of numerical calculation and original Gurson model.

The initial VVF parameter $f_{0}$ is determined by observation of micrograph of virgin material [21, 22] or calibration [23].For AA6061 aluminum alloy, value of initial VVF is provided by several researchers such as Agarwal et al. [22] $\left(f_{0}=\right.$ $0.0014), \mathrm{Xu}$ et al. [21] $\left(f_{0}=0.0025\right)$, Shen et al. [23] $\left(f_{0}=0.0005\right)$. Therefore, a suitable range for the value of $f_{0} \mathrm{VVF}$ of AA6061-T6 can be lie in (0.0005-0.0025).

The parameter $s_{N}$ can be explained through a little metrology significance of nucleated strain measurements. The distribution of nucleated strain values $\varepsilon_{N}$ is assumed to obey a normal distribution with a standard deviation $s_{N}$. Qualitatively, a low standard deviation shows that the values of nucleated strain $\varepsilon_{N}$ tend to be close to the mean (also called the expected value) of the data set, while a high standard deviation indicates that the values of nucleated strain $\varepsilon_{N}$ are spread out over a wider range of values. In this work, a good quality of nucleated strain measurements is assumed to obtain so that value of standard deviation $s_{N}$ of 0.05 is selected.

Two parameters $\varepsilon_{N}$ and $f_{N}$ are usually used as 
the fitting parameters. In practice, it is difficulty to recognize exactly the moment at void nucleation so that the value of nucleated strain $\varepsilon_{N}$ is relatively selected based on onset of material damage [19]. Accordingly, a comparison of force vs. displacement curve between experiment and finite element method (FEM) result of pure Hill48 plasticity theory (no damage) is performed to estimate the value of nucleated strain $\varepsilon_{N}$.

The mesh size of $0.5 \mathrm{~mm} \times 0.5 \mathrm{~mm}$ at critical zone is used to mesh for dog-bone specimen. The displacement controlled load is applied to top edge of specimen. The element type of $3 \mathrm{D}$, reduced integration, 8-nodes (C3D8R) used for dog-bone specimen.
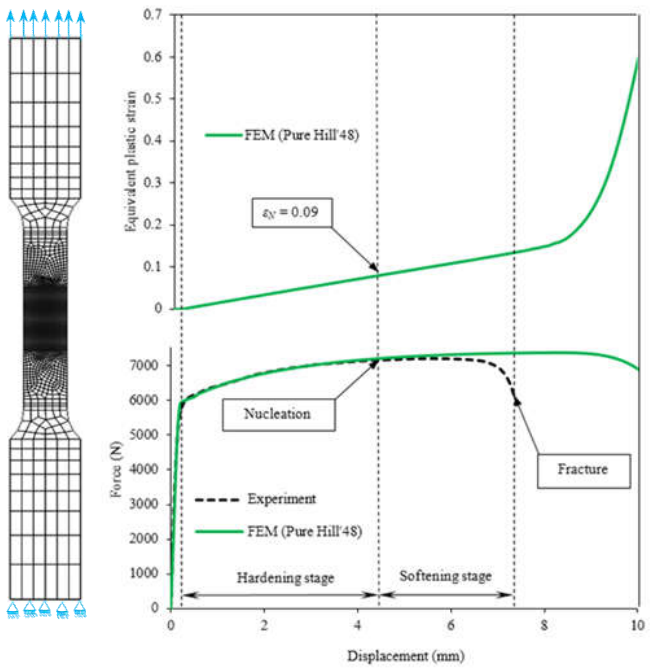

Figure 4. Graphics of determination of nucleated strain $\varepsilon_{N}$

Values of nucleated, critical and fractured VVF $\left(f_{N}, f_{C}, f_{F}\right)$ are calibrated by matching loaddisplacement curve of dog-bone specimen between experiment and FEM.

The FEM simulations are performed for nine values of $f_{N}=0.01,0.015,0.02,0.025,0.03,0.035$, $0.04,0.045,0.05$. A best matched result of loaddisplacement curve between FEM and experiment is selected to fit the values of $f_{C}$ and $f_{F}$ in next step.

The evolution stage of VVF from $f_{C}$ to $f_{F}$ increased more rapid than that of previous period due to the coalescence of micro-voids lead to quick losing of loading carrying of matrix material. There are 25 possible combinations of $f_{C}$ and $f_{F}$ from TABLE . However, because of the constrain $f_{C} \leq f_{F}$ so that have only 24 runs in ABAQUS is possible to obtain a best combination of $\left(f_{C}, f_{F}\right)$ pair that matches the experimental curve.

Finally, the best fit parameters for predicting of ductile fracture are given in TABLE .

The displacement - load curve corresponding to the best fitted material parameters are presented in Figure 5.

TABLE 3

THE VALUES OF CRITICAL AND FRACTURE VVF FOR CALIBRATION

\begin{tabular}{cccccc}
\hline \hline$f_{\mathrm{C}}$ & 0.015 & 0.035 & 0.06 & 0.08 & 0.15 \\
\hline$f_{\mathrm{F}}$ & 0.08 & 0.15 & 0.17 & 0.2 & 0.25 \\
\hline \hline
\end{tabular}

TABLE 4

BEST FIT VALUES OF MATERIAL PARAMETERS FOR DUNG MODEL

\begin{tabular}{|r|r|r|r|r|r|r|r|}
\hline$q_{1}$ & $q_{2}$ & $f_{F}$ & $f_{C}$ & $f_{0}$ & $\varepsilon_{N}$ & $s_{N}$ & $f_{N}$ \\
\hline 1.5 & 2.25 & 0.15 & 0.035 & 0.0018 & 0.09 & 0.05 & 0.03 \\
\hline
\end{tabular}

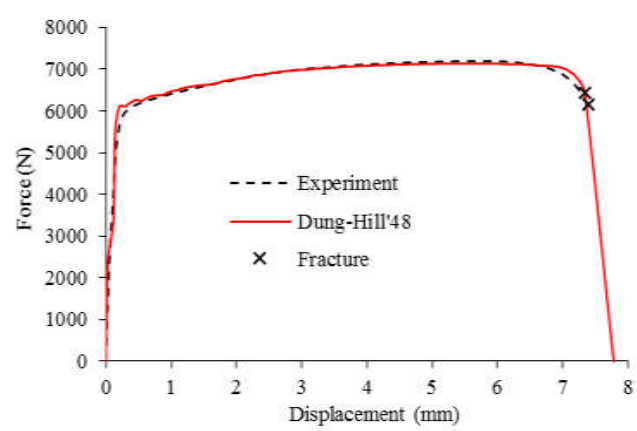

Figure 5. The displacement - load curve after calibration

\section{FORMING LIMIT CURVE}

\subsection{Nakajima test}

The Nakajima's type deep drawing is conducted for the seven specimens with waist width $\mathrm{w}=30$, $55,70,90,120,145$ and the circular shape as Figure $6 \mathrm{a}$. The setup of deep drawing is presented in Figure $6 \mathrm{~b}$. The blank used mesh type of 3D, 8nodes, reduced integration (C3D8R) whereas the punch, holder and die are assumed absolute hard with $3 \mathrm{D}$ analytical rigid type. The initial mesh size at analysis zone is $1.0 \mathrm{~mm} \times 1.0 \mathrm{~mm}$. Three element layers through the thickness of blank are used. The blank holding force $F_{\text {hold }} \approx 450 \mathrm{kN}$ is used to avoid any sliding phenomenon and early damage at the blank holding region. The friction coefficient between the blank and punch surfaces is 0.03 whereas the friction coefficient value of 0.1 on all remain contact surfaces is adopted.
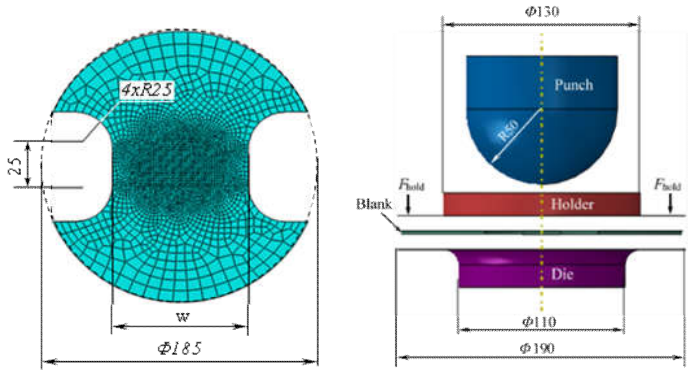

Figure 6 (a) Blank and (b) deep drawing setup (unit: mm) 
After the blank is clamped and the die is fixed, the blank is stretched by moving the punch in vertical direction until its fracture occurs.

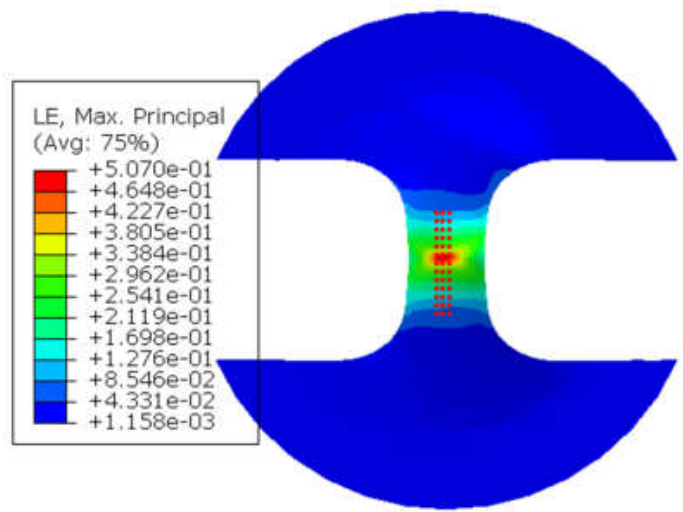

(a)

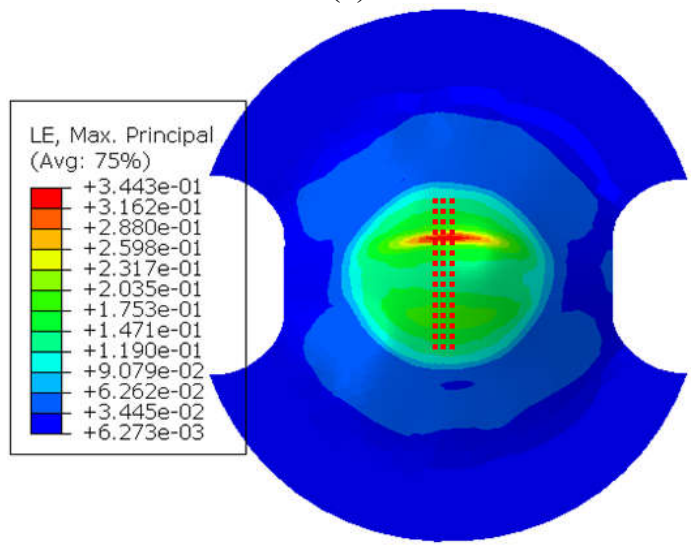

(b)

Figure 7 The extracted path along cross section of W30 and W120 specimens

The limit strains are then determined based on cross-section method that its basic concept is the analysis of the measured strain data along predefined cross sections at onset necking time. The detail procedure of this method is given in ISO 12004-2:2008 - part 2 standard. Accordingly, the principal strain average value of three extracted paths along cross section of each specimen (Figure 7) are taken to fit an inverse parabola.

The best fit inverse parabola is limited by the fit boundaries that presented through the inner (purple dot square line) and outer (green solid line) fit window limits as Figure 8.

The size of inner fit window $\left(\mathrm{L}_{0}\right)$ is determined by the highest peaks of the second derivative of the second order parabola that regressed by three consecutive points of principal strain data within a range of $6 \mathrm{~mm}$.

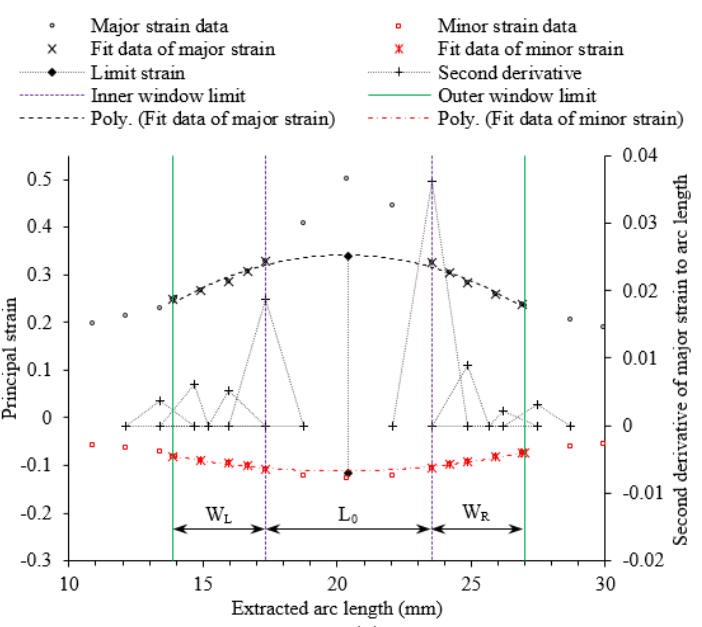

(a)

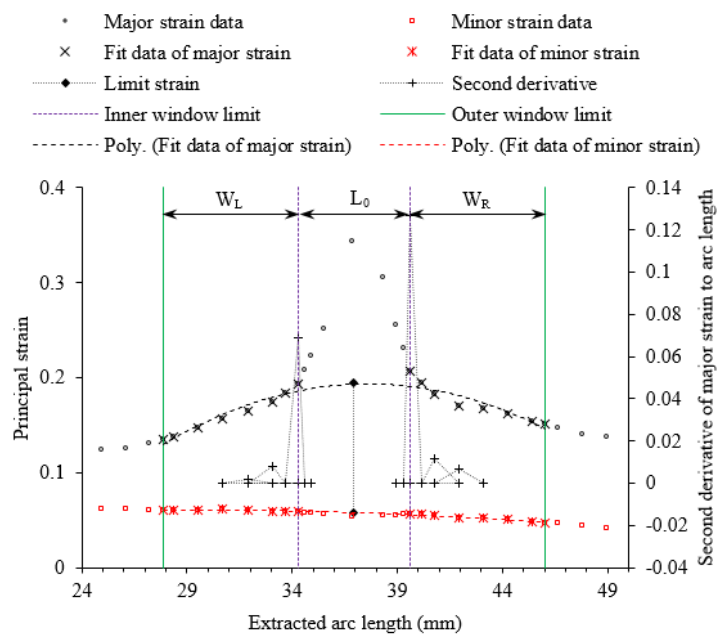

(b)

Figure 8 The curve fit of the principal strain data and the limit strain determination . (a) W30 and (b) W120 specimens

The size of the outer limit window should have at least 5 points and calculated as follows:

$$
\mathrm{W}_{\mathrm{L}}=\mathrm{W}_{\mathrm{R}}=\mathrm{W}_{\mathrm{F}} / 2
$$

Where $\mathrm{W}_{\mathrm{L}}$ left fit window width, $\mathrm{W}_{\mathrm{R}}$ right fit window width

$$
\mathrm{W}_{\mathrm{F}}=10\left[1+\left(\bar{\varepsilon}_{2} / \bar{\varepsilon}_{1}\right)\right]
$$

With

$$
\begin{aligned}
& \bar{\varepsilon}_{2}=1 / 2\left(\varepsilon_{2, B L}+\varepsilon_{2, B R}\right) \\
& \bar{\varepsilon}_{1}=1 / 2\left(\varepsilon_{1, B L}+\varepsilon_{1, B R}\right)
\end{aligned}
$$

The subscripts "BL" and "BR" are used for $\varepsilon_{1}$ and $\varepsilon_{2}$ of the left and right inner boundaries, respectively.

After determination of fit boundaries, the inverse best fit parabola is fitted by all data points within fit window $\left(\mathrm{W}_{\mathrm{L}}\right.$ and $\left.\mathrm{W}_{\mathrm{R}}\right)$. The resulting value in the crack position is the wanted limits for principal strains $\varepsilon_{1}$ and $\varepsilon_{2}$. 


\section{$6.2 M-K$ model}

The Marciniak-Kuczynski (M-K) model is probably the most well-known and widely used to predict analytical FLC curve [24]. Marciniak and Kuczynski introduced imperfections into sheets to describe necking condition. This theory based on the material inhomogeneity assumption, i.e., there is groove which is perpendicular to the axial of maximum principal stress on the sheet surface (see Figure 9). This initial inhomogeneity grows continuously and eventually becoming a localized necking. From the Fig.9, the zone (b) is groove zone, it is assumed the zone (a) is homogeneous zone and obey uniform proportional loading states. The $x, y, z$ axes correspond to rolling, transverse and normal directions of the sheet, whereas 1 and 2 represent the principal stress and strain directions in the homogeneous region. Meanwhile, the set of axes aligned to the groove is represented by $n, t, z$ axes, where $t$ is the longitudinal one. In the sheet metal forming process, the material is firstly under plastic deformation with constant incremental stretching until maximum force happen. The M-K model assumes the flow localization occurs in the groove when a critical strain is reached in the homogeneous region. Then, the values of strain increment in two regions are compared with specific criterion (e.g., $\mathrm{d} \varepsilon_{1 b}>10 \mathrm{~d} \varepsilon_{1 a}$ ) and finally the material major and minor strain limits are obtained on the forming limit diagrams.

Because of $\mathrm{M}-\mathrm{K}$ model based on an assumption of plane stress state so that Hill48 yield criterion can be written as follow

$$
\begin{aligned}
& \sigma_{i}=\left[\sigma_{1}^{2}+\frac{R_{0}\left(1+R_{90}\right)}{R_{90}\left(1+R_{0}\right)} \sigma_{2}^{2}-\frac{2 R_{0}}{1+R_{0}} \sigma_{1} \sigma_{2}\right]^{1 / 2} \\
& \eta=\frac{\sigma_{i}}{\sigma_{1}}=\left[1+\frac{R_{0}\left(1+R_{90}\right)}{R_{90}\left(1+R_{0}\right)} \alpha^{2}-\frac{2 R_{0}}{1+R_{0}} \alpha\right]^{1 / 2}
\end{aligned}
$$

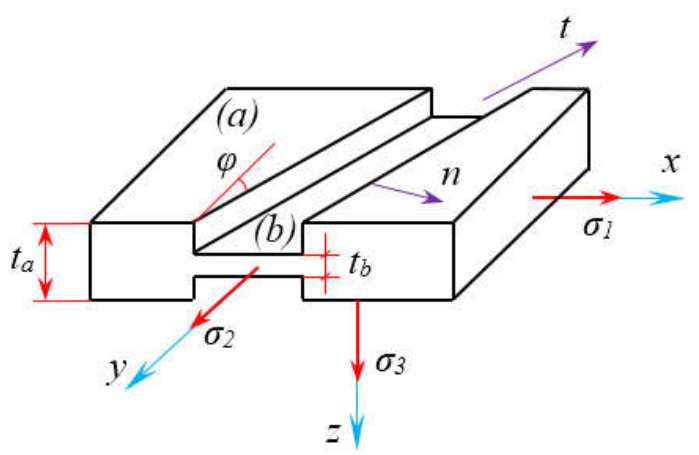

Figure 9 Marciniak-Kuczynski (M-K) model

Because of $\mathrm{M}-\mathrm{K}$ model based on an assumption of plane stress state so that Hill48 yield criterion can be written as follow

$$
\begin{aligned}
& \sigma_{i}=\left[\sigma_{1}^{2}+\frac{R_{0}\left(1+R_{90}\right)}{R_{90}\left(1+R_{0}\right)} \sigma_{2}^{2}-\frac{2 R_{0}}{1+R_{0}} \sigma_{1} \sigma_{2}\right]^{1 / 2} \\
& \eta=\frac{\sigma_{i}}{\sigma_{1}}=\left[1+\frac{R_{0}\left(1+R_{90}\right)}{R_{90}\left(1+R_{0}\right)} \alpha^{2}-\frac{2 R_{0}}{1+R_{0}} \alpha\right]^{1 / 2}
\end{aligned}
$$

The behavior of material can be represented in the form of power law

$$
\sigma_{i}=K \bar{\varepsilon}_{i}^{n} \dot{\bar{\varepsilon}}_{i}^{m}
$$

Where $n$ hardening exponent, $m$ strain rate exponent.

The ratio of the principal stress and strain are defined as follows:

$$
\alpha=\frac{\sigma_{2}}{\sigma_{1}}, \rho=\frac{\varepsilon_{2}}{\varepsilon_{1}}=\frac{d \varepsilon_{2}}{d \varepsilon_{1}}
$$

The associated flow rule is expressed by

$$
d \varepsilon_{1}=d \gamma \frac{\partial \sigma_{i}}{\partial \sigma_{1}} \text { and } d \varepsilon_{2}=d \gamma \frac{\partial \sigma_{i}}{\partial \sigma_{2}}
$$

The yield criterion can be rewritten as follows

$$
\begin{aligned}
& \frac{d \varepsilon_{1}}{R_{90} \sigma_{1}+R_{0} R_{90}\left(\sigma_{1}-\sigma_{2}\right)}=\frac{d \varepsilon_{2}}{R_{0} \sigma_{2}-R_{0} R_{90}\left(\sigma_{1}-\sigma_{2}\right)} \\
& =\frac{-d \varepsilon_{3}}{R_{90} \sigma_{1}+R_{0} \sigma_{2}}=\frac{-d \bar{\varepsilon}_{i}}{R_{90}\left(1+R_{0}\right) \bar{\sigma}_{i}}
\end{aligned}
$$

Thus, the strain rate can be written as follows:

$$
\rho=\frac{d \varepsilon_{2}}{d \varepsilon_{1}}=\frac{R_{0}\left(1+R_{90}\right) \alpha-R_{0} R_{90}}{R_{90}\left(1+R_{0}\right)-R_{0} R_{90} \alpha}
$$

The ratio of strain rate can be calculated

$$
\begin{aligned}
& d \varepsilon_{3}=d t / t \\
& d \varepsilon_{3}=-\frac{R_{90}+R_{0} \alpha}{R_{90}+R_{0} R_{90}(1-\alpha)} d \varepsilon_{1}=-\frac{R_{90}+R_{0} \alpha}{R_{0} \alpha-R_{0} R_{90}(1-\alpha)} d \varepsilon_{2}
\end{aligned}
$$

Introducing a new parameter $\beta$ and using eq. (22)

$$
\beta=\frac{d \varepsilon_{i}}{d \varepsilon_{1}}=\frac{R_{90}\left(R_{0}+1\right) \eta}{R_{90}\left[1+R_{0}(1-\alpha)\right]}
$$

The ratio of initial thickness between (b) and (a) zones

$$
f_{0(m k)}=\frac{t_{b 0}}{t_{a 0}}
$$

Because of thickness strain $\varepsilon_{3}=\ln \left(t / t_{0}\right)$ so that the current thickness of sheet can be calculated as $t=t_{0} \exp \left(\varepsilon_{3}\right)$. The present thickness ration is determined as follow

$$
\frac{t_{b}}{t_{a}}=\frac{t_{b 0}}{t_{a 0}} \exp \left(\varepsilon_{3 b}-\varepsilon_{3 a}\right)
$$




$$
\begin{aligned}
& \text { or } \\
& f_{m k}=f_{0(m k)} \exp \left(\varepsilon_{3 b}-\varepsilon_{3 a}\right)
\end{aligned}
$$

The equilibrium condition requires that the applied load remains constant between (a) and (b) zone, therefore

$$
F_{1 a}=F_{1 b}
$$

If the sheet width is a unity then

$$
\begin{aligned}
& \sigma_{1 a} t_{a}=\sigma_{1 b} t_{b} \\
& \text { or } \\
& \sigma_{1 a}=f_{m k} \sigma_{1 b}
\end{aligned}
$$

From eq. (18)

$\eta_{a} \sigma_{i a}=f_{m k} \eta_{b} \sigma_{i b}$

From eq. (19)

$$
\eta_{a}\left(\bar{\varepsilon}_{i a}+d \bar{\varepsilon}_{i a}\right)^{n} \dot{\bar{\varepsilon}}_{i a}^{m}=f_{m k} \eta_{b}\left(\bar{\varepsilon}_{i b}+d \bar{\varepsilon}_{i b}\right)^{n} \dot{\bar{\varepsilon}}_{i b}^{m}
$$

From eq. (29)

$\varphi_{a}\left(\bar{\varepsilon}_{i a}+d \bar{\varepsilon}_{i a}\right)^{n} \dot{\bar{\varepsilon}}_{i a}^{m}=f_{0(m k)} \exp \left(\varepsilon_{3 b}-\varepsilon_{3 a}\right) \varphi_{b}\left(\bar{\varepsilon}_{i b}+d \bar{\varepsilon}_{i b}\right)^{n} \dot{\bar{\varepsilon}}_{i b}^{m}$

From eq. (23), (30) and (31), the strain relation between the (a) and (b) zones is given as follow

$$
\begin{aligned}
& \eta_{a}\left(\bar{\varepsilon}_{i a}+d \bar{\varepsilon}_{i a}\right)^{n}\left(\frac{\beta_{a}}{\rho_{a}}\right)^{m} \\
& =f_{0(m k)} \exp \left(\varepsilon_{3 b}-\varepsilon_{3 a}\right) \eta_{b}\left(\bar{\varepsilon}_{i b}+d \bar{\varepsilon}_{i b}\right)^{n}\left(\frac{\beta_{b}}{\rho_{b}}\right)^{m}
\end{aligned}
$$

In general, the equilibrium equation (36) can be solved numerically by using the supplementary equations (18), (23) and (26). Given a stress ratio in (a) zone $\left(\alpha_{\mathrm{a}}\right)$ and a finite increment of strain is also imposed in (a) zone $\left(\varepsilon_{\mathrm{a}}=0.001\right)$. The values of hardening exponent $n=0.179$ and of strain rate exponent $m=0$ are chosen. Ratio of initial thickness between (b) and (a) zones $f_{0(m k)}=0.996$.

Then, the numerical computation is performed by using a computational program, e.g. MatLab language, to determine the limit strain of each strain path in the FLC. The limit strains in (a) zone $\left(\varepsilon_{1 \mathrm{a}}, \varepsilon_{2 \mathrm{a}}\right)$ are determined once condition $\left(\mathrm{d} \varepsilon_{1 \mathrm{~b}} / \mathrm{d} \varepsilon_{1 \mathrm{a}}>\right.$ $10)$ is satisfied.

\subsection{Hill model}

Hill [25] proposed a model to describe the curve on the left side of the FLC $\left(\varepsilon_{2}<0\right)$ based on the local necking condition. Principal strains are calculated as follows,

$$
\varepsilon_{1}=\frac{n}{1+\beta} \text { and } \varepsilon_{2}=\frac{n \beta}{1+\beta}
$$

Where $\beta=d \varepsilon_{2} / d \varepsilon_{1}$ denotes strain ratio. According to eq. (37), the FLC calculated based on
Hill's model is only dependent on the hardening coefficient of $n=0.179$ and strain ratio $\beta$ that lie in range from -0.5 to zero.

\subsection{Swift model}

Swift [16] introduced a criterion for predicting FLC based on the onset of diffuse necking criterion.

$$
\begin{aligned}
& \varepsilon_{1}=\frac{2 n\left(1+\beta+\beta^{2}\right)}{(1+\beta)\left(2 \beta^{2}-\beta+2\right)} \\
& \varepsilon_{1}=\frac{2 n \beta\left(1+\beta+\beta^{2}\right)}{(1+\beta)\left(2 \beta^{2}-\beta+2\right)}
\end{aligned}
$$

It is important to remark that, for plane strain $(\beta$ $=0)$ and equibiaxial tension $(\beta=1)$. Similar to Hill model, given hardening coefficient of $n=0.179$ and strain ratio $\beta$ that lie in range from zero to 1.0, the right side of FLC curve is plotted in Fig. 10.

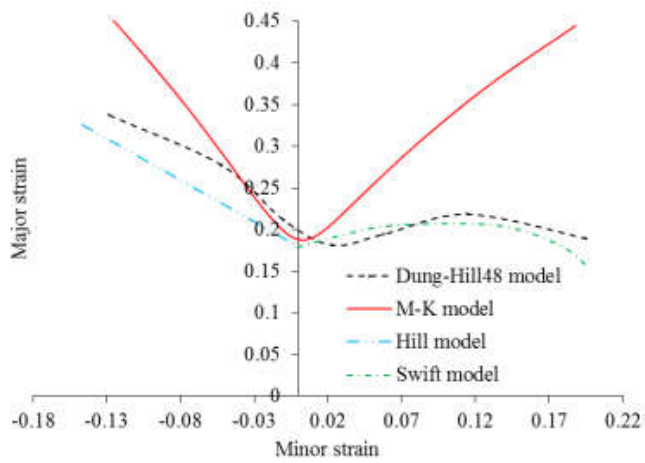

Figure 10. FLC curve of AA6061-T6 aluminum alloy sheet

Finally, the FLC curve of AA6061-T6 sheet is obtained by the Nakajima deep drawing simulation using a porous ductile model and the analytical model as shown in Figure 0. The results show that the FLC of three models are consistent with each other at plane strain state and the FLC curve shape of Dung-Hill48 model is agree with that of Hill and Swift models. While that the M-K model displays a big shift large compare to two remaining models.

\section{CONCLUSION}

In this study, we present a FLC determination of AA6061-T6 aluminum alloy sheet. Material properties and anisotropy coefficients were obtained from tensile test. Applying Dung's porous ductile model to determined FLC through numerical simulation of Nakajima deep drawing. The inverse parabolic fit technique that based on 
ISO 12004-2:2008-part standard is used to achieve the limit strain values in forming process. Using the famous theory models of the FLC calculation by $\mathrm{M}-\mathrm{K}$, Swift and Hill, the analytical FLC curve is proposed. The analytical FLC curve shape of Hill and Swift models agrees with that of the numerical data whereas the predicted FLC curve in biaxial loading states using M-K model is fairly large deviation from that of remaining models.

\section{REFERENCES}

[1] Z. Marziniak and K. Kuczynski, "Limit strain in the process of stretch-forming sheet metals," Int. J. Mech. Sci, vol. 9, pp. 609-620, 1967.

[2] S. Dicecco, C. Butcher, M. Worswick, E. Boettcher, E. $\mathrm{Chu}$, and C. Shi, "Determination of forming limit diagrams of AA6013-T6 aluminum alloy sheet using a time and position dependent localized necking criterion," in IOP Conference Series: Materials Science and Engineering, 2016, vol. 159, no. 1, p. 012009: IOP Publishing.

[3] A. Kami, B. M. Dariani, A. S. Vanini, D. S. Comsa, and D. Banabic, "Numerical determination of the forming limit curves of anisotropic sheet metals using GTN damage model," Journal of Materials Processing Technology, vol. 216, pp. 472-483, 2015.

[4] W. Hotz, M. Merklein, A. Kuppert, H. Friebe, and M. Klein, "Time dependent FLC determination comparison of different algorithms to detect the onset of unstable necking before fracture," in Key Engineering Materials, 2013, vol. 549, pp. 397-404: Trans Tech Publ.

[5] F. A. McClintock, "A Criterion for Ductile Fracture by the Growth of Holes," Journal of Applied Mechanics, vol. 35, no. 2, pp. 363-371, 1968.

[6] J. R. Rice and D. M. Tracey, "On the ductile enlargement of voids in triaxial stress fields," Journal of the Mechanics and Physics of Solids, vol. 17, no. 3, pp. 201217, 6// 1969.

[7] N. L. Dung, "Three Dimensional Void Growth in Plastic Materials," Mechanics Research Comunications, vol. 19, no. 3, p. 227, 1992.

[8] K. Kolasangiani, M. Shariati, and K. Farhangdoost, "Prediction of forming limit curves (FLD, MSFLD and FLSD) and necking time for SS304L sheet using finite element method and ductile fracture criteria," Journal of Computational And Applied Research In Mechanical Engineering, vol. 4, 2015.

[9] R. Hill, "A theory of the yielding and plastic flow of anisotropic metals," in Proceedings of the Royal Society of London A: Mathematical, Physical and Engineering Sciences, 1948, vol. 193, no. 1033, pp. 281-297: The Royal Society.

[10] R. v. Mises, "Mechanik der plastischen Formänderung von Kristallen," ZAMM-Journal of Applied Mathematics and Mechanics/Zeitschrift für Angewandte Mathematik und Mechanik, vol. 8, no. 3, pp. 161-185, 1928.

[11] A. L. Gurson, "Continuum theory of ductile rupture by void nucleation and growth: Part I-Yield criteria and flow rules for porous ductile media," Journal of engineering materials and technology, vol. 99, no. 1, pp. $2-15,1977$

[12] V. Tvergaard and A. Needleman, "Analysis of the cupcone fracture in a round tensile bar," Acta Metallurgica, vol. 32, no. 1, pp. 157-169, 1// 1984.
[13] N. Aravas, "On the numerical integration of a class of pressure-dependent plasticity models," International Journal for Numerical Methods in Engineering, vol. 24, no. 7, pp. 1395-1416, 1987.

[14] H. H. Nguyen, T. N. Nguyen, and H. C. Vu, "Implementation and Application of Dung's Model to Analyze Ductile Fracture of Metallic Material," in AETA 2015: Recent Advances in Electrical Engineering and Related Sciences: Springer, 2016, pp. 903-913.

[15] E. ASTM, "Standard test methods for tension testing of metallic materials," Annual book of ASTM standards. ASTM, 2001.

[16] H. W. Swift, "Plastic instability under plane stress," Journal of the Mechanics and Physics of Solids, vol. 1, no. 1, pp. 1-18, 10// 1952.

[17] Z. Li, B. Bilby, and I. Howard, "A study of the internal parameters of ductile damage theory," Fatigue \& Fracture of Engineering Materials \& Structures, vol. 17, no. 9, pp. 1075-1087, 1994.

[18] Z. Zhang, "A sensitivity analysis of material parameters for the Gurson constitutive model," Fatigue \& Fracture of Engineering Materials \& Structures, vol. 19, no. 5, pp. 561-570, 1996.

[19] R. Kiran and K. Khandelwal, "Gurson model parameters for ductile fracture simulation in ASTM A992 steels," Fatigue \& Fracture of Engineering Materials \& Structures, vol. 37, no. 2, pp. 171-183, 2014.

[20] V. Tvergaard, "On localization in ductile materials containing spherical voids," (in English), International Journal of Fracture, vol. 18, no. 4, pp. 237-252, 1982/04/01 1982

[21] F. Xu, S. Zhao, and X. Han, "Use of a modified Gurson model for the failure behaviour of the clinched joint on A16061 sheet," Fatigue \& Fracture of Engineering Materials \& Structures, vol. 37, no. 3, pp. 335-348, 2014.

[22] H. Agarwal, A. Gokhale, S. Graham, and M. Horstemeyer, "Void growth in 6061-aluminum alloy under triaxial stress state," Materials Science and Engineering: A, vol. 341, no. 1, pp. 35-42, 2003.

[23] Y. Shen, T. F. Morgeneyer, J. Garnier, L. Allais, L. Helfen, and J. Crépin, "Three-dimensional quantitative in situ study of crack initiation and propagation in AA6061 aluminum alloy sheets via synchrotron laminography and finite-element simulations," Acta Materialia, vol. 61, no. 7, pp. 2571-2582, 2013.

[24] Z. Marciniak and K. Kuczyński, "Limit strains in the processes of stretch-forming sheet metal," International journal of mechanical sciences, vol. 9, no. 9, pp. 609IN1613-612IN2620, 1967.

[25] R. Hill, "On discontinuous plastic states, with special reference to localized necking in thin sheets," Journal of the Mechanics and Physics of Solids, vol. 1, no. 1, pp. 1930, 1952/10/01 1952. 


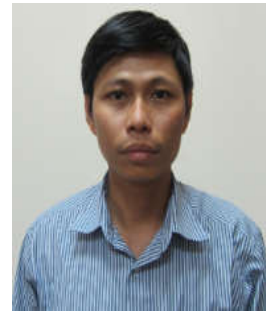

Nguyen Huu Hao received the B.E. (2004), Mechanical Engineering, Military Technical Academy (MTA), Vietnam, M.E. (2012) degree in engineering mechanics from Ho Chi Minh City University of Technology - VNU-HCM.

$\mathrm{He}$ is a Ph.D. Candidate at Department of Engineering Mechanics, Ho Chi Minh City University of Technology - VNU-HCM. His current interests include the modelling and predicting of ductile fracture of metallic materials.

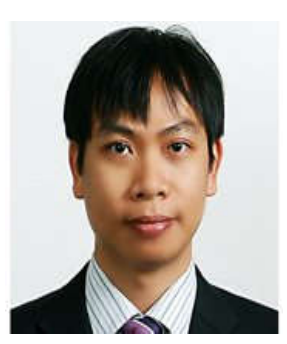

Nguyen Ngoc Trung B.E. (2001, Aeronautical Engineering, Ho Chi Minh City University of Technology - VNU-HCM, Vietnam), M.Sc. (2003, Mechanics of Construction, Liège University, Belgium), Ph.D. (2008, Aerospace Engineering, Konkuk University, South Korea)

He is current working as a postdoctoral research associate at Purdue University, IN, USA. His research interests include constitutive modeling of materials, materials design, and mechanics of advanced manufacturing processes.

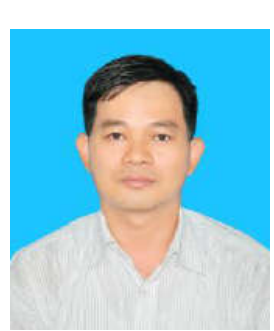

Vu Cong Hoa received the B.E. (1995), M.E. (2000,), and Dr.Eng. (2006) in Mechanical Design from Chonbuk National University, South Korea.

He is an Associate Professor, at Department of Engineering

Mechanics, Ho Chi Minh City University of Technology - VNU-HCM. His current interests include estimating of microscopic ductile fracture of metallic materials and micro-mechanical behavior of composite materials. 


\section{Xác định đường cong giới hạn gia công tấm hợp kim nhôm AA6061-T6}

Nguyễn Hữu Hào, Nguyễn Ngọc Trung, Vũ Công Hoà

Tóm tắt - Đường cong giới hạn gia công được sử dụng trong phân tích gia công kim loại dạng tấm nhằm xác định các giá trị ứng suất hoặc biến dạng tới hạn mà tại các giá trị tới hạn này vật liệu sẽ bị hư hòng khi chịu biến dạng dẻo, ví dụ như quá trình dập kim loại. Bài báo này nhằm dự đoán giới hạn gia công của tấm hợp kim nhôm AA6061-T6 dựa trên mô hình nứt dẻo vi mô. Mô hình cơ sở được lập trình dưới dạng chương trình vật liệu người dùng kết hộp với mã phần tử hữu hạn trong phần mềm ABAQUS/Explicit. Các thí nghiệm kéo đơn trục được thực hiện để xác định ứng xử cơ tính của vật liệu. Các tham số đầu vào của mô hình cơ sở được xác định dựa trên phương pháp bán kinh nghiệm. Để đạt được các trạng thái biến dạng khác nhau, các mẫu dập sâu Nakajima được sử dụng để mô phỏng và kỹ thuật hồi quy parapol ngược theo chuẩn ISO 124004-2:2008 được áp dụng để tính các giá trị biến dạng giới hạn. Các kết quả đạt được thông qua mô phỏng số sẽ được so sánh với các mô hình giải tích như $M-K$, Hill và Swift.

Tù khóa - đường cong giới hạn gia công, tăng trưởng lỗ hổng vi mô, dập Nakajima, mô hình N. L. Dung 